\title{
ERRATUM
}

\section{Erratum for Kamal et al., A Drug-Disease Model Describing the Effect of Oseltamivir Neuraminidase Inhibition on Influenza Virus Progression}

\author{
Mohamed A. Kamal, ${ }^{\text {a }}$ Ronald Gieschke, ${ }^{\text {b }}$ Annabelle Lemenuel-Diot, ${ }^{\text {b }}$ Catherine A. A. Beauchemin, ${ }^{c}$ Patrick F. Smith, ${ }^{\text {d,e }}$ \\ Craig R. Rayner ${ }^{\text {d,f }}$
}

Department of Clinical Pharmacology, Roche Pharmaceutical Research and Early Development, New York City, New York, USA; Department of Clinical Pharmacology,

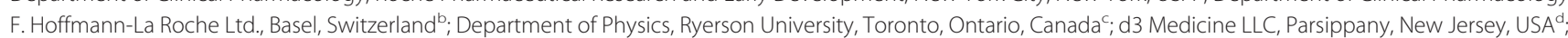
University at Buffalo, School of Pharmacy and Pharmaceutical Sciences, Buffalo, New York, USA ; Monash Institute of Pharmaceutical Sciences, Melbourne, Australia ${ }^{\dagger}$

Volume 59, no. 9, p. 5388-5395, 2015. Page 5391, Table 2: It was brought to our attention that there was an inadvertent error in reporting the residual error term $\left(\sigma_{\text {error }}\right.$, Table 2$)$ in our model. The minor error is isolated and has no impact on the stated objectives of the paper, the integrity or interpretation of the results, and the final conclusions. Because the pharmacodynamic effect is measured and modeled as $\log _{10}$ of $\mathrm{TCID}_{50} / \mathrm{ml}$ (viral load), it should in fact be reported and defined as an additive error term in log and not a proportional term as a CV\% (coefficient of variation percentage). The additive error term is reported as the standard deviation or square root of the variance provided by NONMEM and, as such, based on the NONMEM output provided in the supplemental material, we report the correct residual error $\left(\sigma_{\text {error }}\right.$, Table 2 ) as 1.07 (square root of 1.15$)$ in $\log \mathrm{TCID}_{50} / \mathrm{ml}$. 